\title{
Análise de Concorrência no Mercado Mundial de Café Verde
}

\author{
Marislei Nishijima ${ }^{1}$, Maria Sylvia Macchione Saes $^{2}$ e \\ Fernando Antonio Slaibe Postali ${ }^{3}$
}

\begin{abstract}
Resumo: A literatura argumenta que o Brasil, embora ainda seja o maior exportador mundial de café verde, tem perdido poder neste mercado, pois a concorrência (rivalidade e probabilidade de entrada) imposta por países como a Colômbia e o Vietnã é forte o suficiente para tornar este mercado bastante competitivo. Assim, este artigo avalia o padrão recente de concorrência do mercado mundial de café verde utilizando uma metodologia econométrica mais usualmente empregada em análise antitruste. Para avaliar o comportamento dos consumidores, foram estimadas as elasticidades-preço da demanda mundial de café verde, por tipo de café, usando o modelo de demanda Logit Multinomial Antitruste. Para avaliar o comportamento de equilíbrio de mercado foram realizados testes de instabilidade de share de quantidade por meio de análise de cointegração em painel. Os resultados apontam para aumento da concorrência à variedade de café brasileiro por parte da demanda e manutenção de sharede quantidades como configuração de equilíbrio de mercado.
\end{abstract}

Palavras-chaves: café verde, mercado internacional, marketshare.

Abstract: Although Brazil is still the world's leading exporter of green coffee, current studies demonstrate that Brazil has been losing power in the market, because the existing competition (rivalry and possibility to enter) imposed by countries, such as Colombia and Vietnam, is strong enough to make this market very competitive. Therefore, this paper assesses the competitive profile in the world market for green coffee using econometric tools usually employed in antitrust analysis. To evaluate the consumer behavior, price elasticity of the world demand for green coffee was estimated, by coffee type, using the Multinomial Logit Demand model. To evaluate the supply behavior, tests for market share instability were conducted, in terms of quantity, by using cointegration in panel data. Results reveal an increased competition for the Brazilian coffee from the point of view of the demand, with the maintenance of market shares over time.

Key-words: green coffee, international market, market share.

Classificação JEL: F1, F10, Q17.

1 Professora Associada da USP no curso de Gestão de Políticas Públicas. E-mail: marislei@usp.br

2 Professora Associada da USP no curso de Administração e coordenadora do Cors. E-mail: ssaes@usp.br

3 Professor doutor da USP no curso de Economia. E-mail: postali@usp.br 


\section{Introdução}

O mercado mundial de café apresentou expressivas modificações a partir dos anos 90, particularmente do lado da oferta, com o crescimento de cerca de $30 \%$ da produção mundial entre 1990 e 2010 (ICO, 2010). O principal estímulo a esse crescimento foi a elevação dos preços, em decorrência de sérios problemas climáticos nas regiões produtoras na década de 90 , que, aliada às baixas barreiras à entrada, resultou em forte crescimento do parque cafeeiro na maioria dos países produtores. Merece destaque, entretanto, a inserção do Vietnã no mercado, que se tornou o segundo maior produtor e exportador de café da variedade robusta. Esta variedade possui qualidade e preço inferiores aos da arábica, exportado por Brasil e Colômbia, mas apresenta produtividade mais competitiva (CHI, TUAN e LAN, 2009). O crescimento na produção de café arábica mostrou-se inferior na década de 2000, principalmente o do tipo arábico suave, o mais valorizado no mercado, do qual a Colômbia é a maior ofertante e cuja demanda tem sido suprida em parte pelo café arábica natural brasileiro.

Embora o Brasil ainda seja o maior exportador mundial de café verde, com 30\% do total comercializado, o aumento da oferta do café robusta tem levado alguns pesquisadores a especular sobre a possibilidade de o café vietnamita estar ocupando espaço crescente na composição de blend, principalmente em detrimento do café do tipo arábica natural, do qual o Brasil é grande exportador (SAES, 2009; CUNHA, 2008). Vale lembrar que o café torrado consumido pelos demandantes finais consiste em uma mistura composta de diferentes tipos de café (blends).

As alterações verificadas nos últimos anos convidam a uma reavaliação do papel do Brasil neste mercado, dado que este sempre foi um ofertante com peso significativo. Neste contexto, o objetivo deste artigo é apresentar uma avaliação global das condições de competição recente no mercado internacional de café verde, investigando se o Brasil tem poder significativo na determinação de seus preços.

A questão é relevante, pois, enquanto a oferta mundial de café verde robusta representava menos de um terço do mercado até meados da década de 90, havia evidências de que este era um produto complementar ao café brasileiro, visto que a composição do blend das torrefadoras internacionais combinava ambos os tipos. Nesta composição, o café colombiano seria substituto do café brasileiro (BACHA, 1970). Entretanto, nos anos mais recentes, existem indícios de que estaria ocorrendo uma substituição do café brasileiro pelo café robusta vietnamita, em virtude da expansão da oferta do país asiático (HAEBERLIN et al., 1993) ${ }^{4}$. Este fenômeno tornaria o café verde brasileiro efetivamente um bem substituto tanto do café colombiano quanto do café verde vietnamita, o que implicaria potencial perda de poder de preços por parte do Brasil.

${ }^{4}$ Os autores chegam à conclusão de que, para a demanda do café brasileiro, o café colombiano comporta-se como um bem complementar, e não substituto, pois o café brasileiro é demandado em misturas. 
A fim de investigar se houve mudança no padrão de concorrência no mercado mundial de café nos últimos anos, que teria reduzido a possibilidade do exercício de poder de determinar preços do Brasil, foram utilizadas técnicas provenientes de análise antitruste. Espera-se que a influência da produção do café robusta pelo Vietnã e por outros produtores tenha efeito significativo sobre tal poder. A vantagem de tais técnicas é a reduzida quantidade de informação necessária para a obtenção de estimativas. Além disso, com o fim dos acordos dos países membros daInternational Coffee Organization (ICO), o mercado mundial de café ganhou uma dinâmica que torna o emprego destas técnicas bastante apropriado. Assim, foram empregados testes de raiz-unitária em painel, que combina características de integração (tendência estocástica) de variáveis no longo prazo com informações de painel (vários indivíduos sendo seguidos ao longo do tempo). Esta técnica permite testar empiricamente a existência de concorrência no mercado, conforme Resende e Lima (2005) ${ }^{5}$, propiciada tanto por rivalidade, ou seja, concorrência efetiva imposta pelos produtores já atuantes no mercado, quanto pela possibilidade de entrada de novas empresas. A existência de concorrência, efetiva ou potencial, implica menor probabilidade do exercício do poder de determinar preços. Adicionalmente, foram estimadas as elasticidades-preço da demanda para os principais tipos de café, com vistas a avaliar as atuais características deste mercado.

Além desta introdução, o estudo está estruturado da seguinte maneira: a seção 2 apresenta o histórico e o modelo de interação econômica do mercado internacional de café verde; a seção 3 apresenta a metodologia de análise de concorrência e da estimação de elasticidades-preço da demanda; a seção 4 apresenta os dados utilizados e os resultados obtidos; e, finalmente, a seção 5 apresenta as conclusões.

5 Que realizam estudos semelhantes para a indústria brasileira.

\section{O mercado mundial de café}

O café é uma cultura perene, adaptada à zona tropical e subtropical, sendo cultivado em países em desenvolvimento da África, Ásia e América Latina. Com exceção do Brasil, a bebida é consumida basicamente em países desenvolvidos, onde não existem condições climáticas para seu cultivo, mas há elevado nível de renda per capita. Como resultado geral, o canal básico de comércio desta commodity no mundo se dá entre os países produtores de café com níveis de renda baixo ou médio e os países desenvolvidos, com moderna tecnologia de processamento e altos níveis de renda per capita.

Entre as espécies de café, duas apresentam valor econômico: o arábica (Coffea arabica) e o robusta ${ }^{6}$. A espécie arábica é reconhecida no mercado devido ao seu aroma agradável e pela pequena quantidade de cafeína (1,2\% a 1,3\% mv). Essa variedade sofre ainda uma segmentação de acordo com o beneficiamento do grão pós-colheita. No caso do café arábica natural - cujo maior ofertante é o Brasil - adota-se o processo de beneficiamento seco ao sol, principalmente em Minas Gerais, São Paulo e no Paraná, que são os maiores estados produtores; enquanto isso, o café arábica suave é processado via úmida, cujos maiores produtores são Colômbia, México, El Salvador, Guatemala, Peru, Índia e Quênia (ICO, 2010) $)^{7}$.

6 Existem muitas espécies e variedades de café. As espécies de importância econômica são Coffea arabica e Coffea Cannephora (esta últimaconhecida como robusta). A primeira é a mais conhecida pela sua qualidade e preço superior e é cultivada principalmente na América do Sul e Central, Quênia e Tanzânia, na África. A segunda é cultivada em maior escala no Vietnã, Brasil, Costa do Marfim, Angola, Uganda, Índia e vários outros países da África, Ásia e Oceania. O Brasil é o maior produtor mundial da variedade arábica e o segundo maior da robusta (SAES e FARINA, 1997).

$7 \mathrm{O}$ processamento por via seca é mais antigo e mais simples, requerendo poucos equipamentos. Os grãos são espalhados ao sol em terreiros. À medida que seca, é revolvido com rodos ou com as mãos para produzir uma secagem uniforme. Cerca de $95 \%$ do café arábica produzido no Brasil é seco em terreiro. O processamento 
Figura 1. Produção mundial de café arábica e robusta (mil sacas de 60 kg).

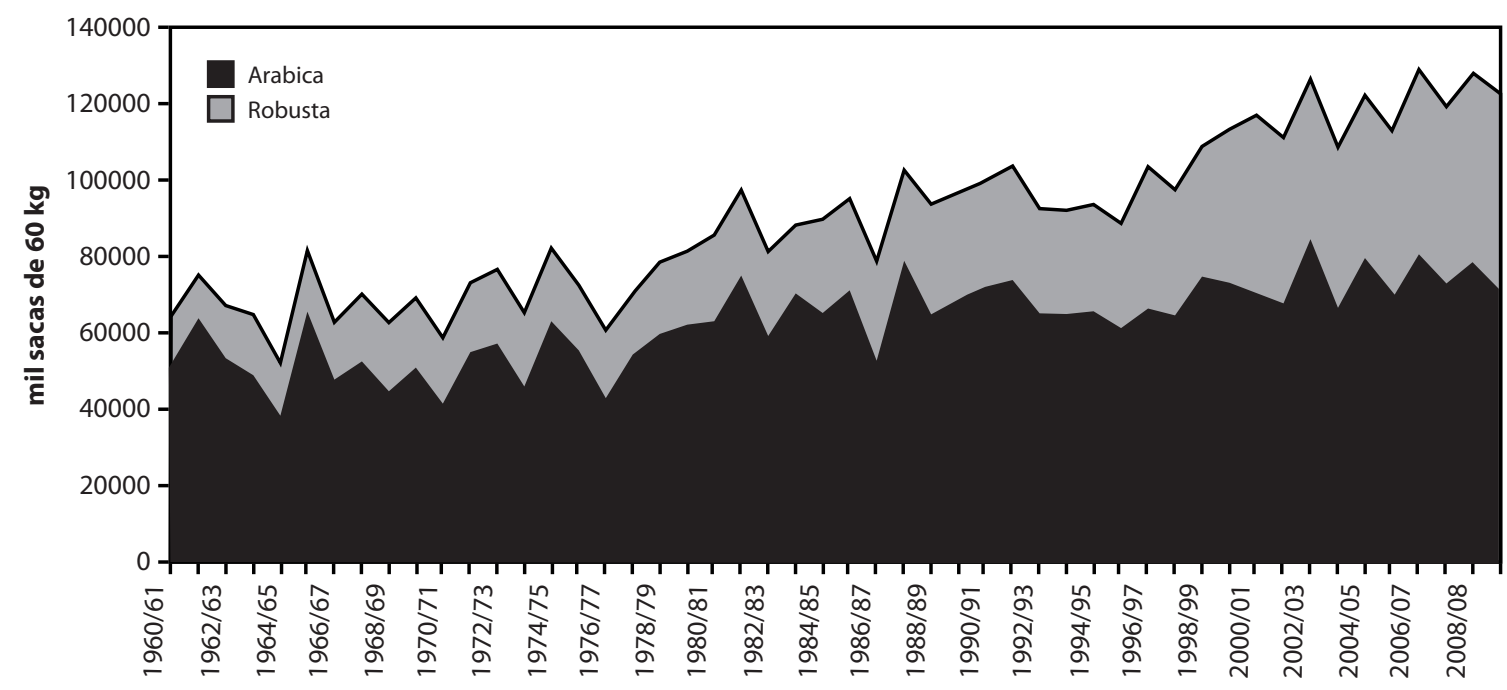

Fonte: ICO (2010).

Já o café robusta (Coffeacannephora) é cultivado em maior escala no Vietnã, no Brasil (Espírito Santo e Rondônia), Costa do Marfim, Angola, Uganda, Índia e outros países da Ásia, África e Oceania. Esse café é menos valorizado pelo mercado, possui menor preço e tem uma alta concentração de cafeína $(2,2 \%$ a $2,5 \% \mathrm{mv})$. Observa-se que, apesar de o Brasil ser o segundo maior produtor mundial de café verde robusta, sua participação no mercado internacional é muito pequena e volátil, pois esta variedade é destinada majoritariamente como insumo para fabricação de café solúvel no mercado interno; este, por sua vez, se destina à exportação e ao mercado doméstico, ou ainda à composição dos blends dos cafés torrado e moído consumidos internamente. Deste modo, quando se fala de exportação brasileira de café verde, trata-se fundamentalmente do tipo arábica.

por via úmida requer o uso de equipamento específico e grande quantidade de água. Em geral, esse método assegura um café verde homogêneo, com poucos grãos defeituosos. O café processado por esse método é considerado de melhor qualidade, resultando em preços mais altos.
As participações desses três segmentos de café (robusta, arábica natural e arábica suave) no mercado internacional têm se modificado ao longo dos anos. O café robusta, que nos anos 1960 representava menos de 19\% do total ofertado mundialmente, passou a responder por mais de 40\% nos anos 1990 (ICO, 2010). O mais impressionante é que, até o início da década de 90, o Vietnã, que até então não produzia café, se transformou no segundo maior produtor e no maior exportador mundial deste segmento. A Figura 1 apresenta o crescimento das produções de café arábica e robusta no mercado internacional. Como se pode verificar, o café do tipo robusta tem crescido a taxas maiores, o que pode ser avaliado pela maior inclinação de uma linha de tendência projetada.

Desde os anos 2000, o Vietnã se tornou o segundo maior exportador mundial de café verde, com $17 \%$ do total, perdendo apenas para o Brasil, que detém 30\% do mercado. A Colômbia, que tradicionalmente ocupava a segunda posição, passou para o terceiro lugar, com $11 \%$ do mercado mundial (ICO, 2010).

O crescimento da produção de café tem sido impulsionado por vários fatores, entre os quais 
Tabela 1. Produção mundial de café por países produtores $(\mathrm{A}=$ arábica e $\mathrm{R}=$ robusta $)$ - milhões de sacas de $60 \mathrm{~kg}$.

\begin{tabular}{lcccccc}
\hline \multicolumn{1}{c}{ Países } & $\begin{array}{c}\mathbf{1 9 6 0 / 6 1 -} \\
\mathbf{1 9 6 9 / 7 0}\end{array}$ & $\begin{array}{c}\mathbf{1 9 7 0 / 7 1 -} \\
\mathbf{1 9 7 9 / 8 0}\end{array}$ & $\begin{array}{c}\mathbf{1 9 8 0 / 8 1 -} \\
\mathbf{1 9 8 9 / 9 0}\end{array}$ & $\begin{array}{c}\mathbf{1 9 9 0 / 9 1 -} \\
\mathbf{1 9 9 9 / 0 0}\end{array}$ & $\begin{array}{c}\mathbf{2 0 0 0 / 0 1 -} \\
\mathbf{2 0 0 7 / 0 8}\end{array}$ & $\begin{array}{c}\mathbf{2 0 0 0 / 0 1 -} \\
\mathbf{2 0 0 7 / 0 8}(\mathbf{\%})\end{array}$ \\
\hline Brasil (A/R) & 25.370 & 19.370 & 26.515 & 27.470 & 39.825 & 33,7 \\
Vietnã (R) & 48 & 66 & 377 & 4.661 & 14.825 & 12,5 \\
Colômbia (A) & 7.815 & 9.476 & 12.514 & 12.797 & 11.663 & 9,9 \\
Indonésia (R/A) & 2.196 & 3.204 & 5.853 & 7.004 & 6.459 & 5,5 \\
Índia (R/A) & 1.131 & 1.757 & 2.478 & 3.562 & 4.771 & 4,0 \\
Etiópia (A) & 2.675 & 3.653 & 4.651 & 4.843 & 4.297 & 3,6 \\
México (A) & 2.218 & 2.7 & 3.125 & 3.631 & 4.23 & 3,6 \\
Guatemala (A) & 1.777 & 2.321 & 2.794 & 3.783 & 3.802 & 3,2 \\
Peru (A) & 823 & 1.025 & 1.206 & 1.575 & 3.02 & 2,6 \\
Honduras (A) & 422 & 841 & 1.439 & 2.328 & 2.973 & 2,5 \\
Uganda (R/A) & 2.688 & 2.712 & 2.732 & 3.247 & 2.701 & 2,3 \\
Costa Marfim (R) & 3.431 & 4.337 & 4.144 & 3.643 & 2.668 & 2,3 \\
Costa Rica (A) & 1.097 & 1441 & 2.247 & 2.526 & 2.057 & 1,7 \\
Outros & 15.527 & 18.934 & 20.757 & 18.359 & 14.88 & 12,6 \\
Total & 67.218 & 71.834 & 90.831 & 99.427 & 118.171 & 100 \\
\hline
\end{tabular}

Fonte: ICO (2010).

se destacam: (i) aumento dos preços, decorrente principalmente de problemas climáticos, já que a demanda tende a crescer de forma estável; (ii) políticas agrícolas das nações produtoras e dos países desenvolvidos visando o combate à pobreza em países pobres; (iii) inovação tecnológica, particularmente com técnicas de fertirrigação que têm resultado em melhora da produtividade; e (iv) desvalorização cambial nos países produtores (SAES, 2009).

A entrada do Vietnã no mercado mundial de café teve como impulso uma política deliberada do Banco Mundial em patrocinar o produto, dado que os preços no mercado internacional estavam relativamente altos, em função de problemas climáticos que haviam acometido a produção brasileira em meados da década de 90. O crescimento da produção, entretanto, foi alavancado pela política cambial vietnamita e pelos baixos custos da mão de obra, quando comparados com a produção dos concorrentes. A média da produção mundial na década de 90 foi de 100 milhões de sacas, ante 118 milhões de sacas nos anos 2000 (Tabela 1).

A demanda, por sua vez, é afetada pela renda, pela política de incentivo ao consumo e por fatores culturais. Devido à reduzida influência de choques exógenos, o consumo de café tem crescido de forma constante, cerca de 1,3\% ao ano (ICO, 2010). O crescimento da produção do café verde robusta, além de acentuar a queda dos preços de forma geral, tendeu a aumentar o diferencial entre esses dois tipos, favorecendo a competitividade do robusta, conforme se observa na Figura 2. O gráfico apresenta os preços médios anuais dos cafésarábica e robusta, nas respectivas Bolsas de Futuros (Nova York para o café arábica ${ }^{8}$ e Londres para o café robusta), deflacionados pelo Índice de Preços ao Consumidor ${ }^{9}$ dos Estados Unidos, desde o início da década de 90.

A grande vantagem do café robusta é a maior produtividade e o menor custo de produção. Para aproveitar o crescimento de sua oferta, as grandes processadoras desenvolveram a tecnologia de vaporização, que neutraliza o impacto do sabor sobre a bebida, permitindo o aumento do uso desta variedade em seus blends sem prejudicar

8 O contrato futuro de café negociado na Bolsa de Nova York refere-se ao arábica suave, que tem ágio sobre o café arábica natural (LAZARINI et al., 2000).

9 Fonte: International Financial Statistics do FMI. 
Figura 2. Indicadores de Preços da ICO: suave colombiano, natural brasileiro e robusta (centavos de dólar por libra-peso).

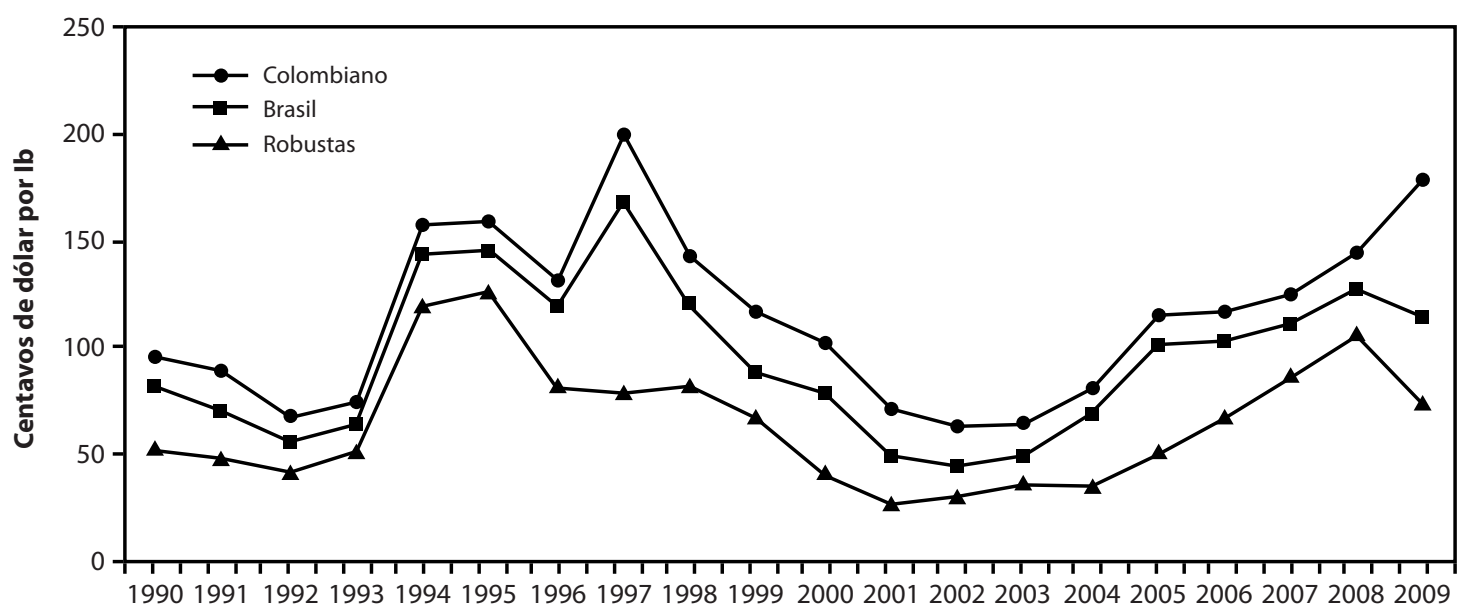

Fonte: ICO (2010).

o paladar (SAES e FARINA, 1999). Além disso, o aumento recente na demanda por café tem sido puxada pelos países em desenvolvimento, particularmente no médio/sudeste Asiático e na Europa Oriental. Tais regiões, tradicionalmente consumidoras de chá, têm preferência pelo consumo de café solúvel de fácil preparo, que é preferencialmente fabricado com o robusta, devido ao seu preço mais competitivo e também por permitir um melhor aproveitamento na extração de sólidos solúveis.

\section{Metodologia}

Tendo em vista este quadro de transformações importantes no mercado mundial de café, que papel o Brasil, líder no mercado por décadas, vem exercendo? Ele é capaz de influenciar os preços de forma significativa? Com o objetivo de lançar luzes sobre essa questão, o objetivo desta seção é utilizar uma metodologia proveniente da análise antitruste a fim de investigar a possibilidade de o Brasil exercer poder de influência sobre os preços mundiais de café. Para avaliar o lado da demanda mundial de café verde, foi estimado um sistema de demanda ALM com vistas a obter estimativas preliminares e mais atuais das elasticidades-preço da demanda. Para avaliar o comportamento dos ofertantes foram realizados testes de instabilidade de market share.

O ALM é um dos sistemas de demanda mais usados em análises antitruste por sua simplicidade e pela reduzida necessidade de dados (WERDEN et al., 1996). Informações sobre preços e quantidades vendidas dos bens em cada mercado são suficientes para se obter os valores das elasticidades-preço dos bens envolvidos. Trata-se de um modelo estimado a partir de dados agregados de mercados, mas que guarda seus principais microfundamentos.

O modelo se baseia na decisão de consumo, na quala utilidade indireta de um agente representativo $i$, ao escolher um produto $j$, pode ser expressa por:

$$
U_{i j}=\alpha_{j}-\beta p_{j}+e_{i j}
$$

em que $p_{j}$ é o preço do bem $j, \beta$ é o coeficiente que mede o impacto do preço sobre a utilidade, $\alpha_{j}$ é um coeficiente que resume todas as percepções de diferenças entre os bens disponíveis à escolha e $e_{i j}$ é um componente estocástico. Em outras palavras, parte-se da hipótese de que a utilidade do agente representativo pode ser decompostaem uma parte determinista e uma parte estocástica, assumindo-se a linearidade do componente determinista em relação ao preço, nos moldes de Werden et al. (1996). 
A escolha adequadada função densidade de probabilidade de $e_{i j}$ como sendo a de valor extremo independente e identicamente distribuída (iid), que pressupõe que os valores não observados são homocedásticos e não correlacionados, redunda em um modelo de probabilidade logística (TRAIN, 2009).

No modelo Logit multinomial, a variável dependente élimitada a escolhas discretas (tipos de bens enumeráveis e finitos) modeladas por função logística, sendo aplicado de maneira adequada a modelos de oligopólio com produtos diferenciados(WERDEN e FROEB, 1994). Assim, o agente representativo faz escolhas discretas sobre um conjunto de $j=1, \ldots, J$ alternativas sobre bens diferenciados.

Nestas condições, e conforme demonstrado por Bem-Akiva e Lerman (1985) e Macfadden (1974), a expressão que define a probabilidade do indivíduo $i$ comprar o bem $j$ é dada por:

$$
\operatorname{Pr}_{i j}=\frac{\exp \left(\alpha_{j}-\beta p_{j}\right)}{\sum_{j=0}^{J} \exp \left(\alpha_{k}-\beta p_{k}\right)}
$$

Note que o indexador do indivíduo $i$ não aparece na equação, tendo em vista a hipótese de que as probabilidades são as mesmas para qualquer indivíduo.Essa simplificação do modelo ilustra o tipo de estrutura imposta com vistas a reduzir o número de parâmetros a serem estimados.

Para a análise antitruste, aplicada neste estudo ao mercado internacional de café verde, é conveniente e possível definir $n$ produtos, de modo que o J-ésimoconfigure oque se convencionou chamar de bem externo (outside good). Trata-se de um produto fictício, que representa a possibilidade de o consumidor simplesmente não comprar nada ${ }^{10}$, embora potencialmente pudesse fazê-lo. A adoção deste bem é importante para garantir que a demanda do mercado não seja perfeitamente inelástica. A soma doinside com o outside good corresponde a uma medida de mercado potencial.

10 De acordo com DeSouza (2009), o bem externo pode representar várias atitudes: esperar para comprar, desistir de comprar, ganhar de presente etc.
Para o caso do mercado internacional de café verde, objeto deste estudo, parte-se da hipótese de que o outside good corresponde a $1 / 4$ do total vendido no mercado ${ }^{11}$. Esse valor foi escolhido devido à falta de informação sobre o que seria o mercado potencial de café verde mundial. Assim, embora o recente aumento de consumo de café em países asiáticos e, mesmo nos Estados Unidos, tenha sinalizado um mercado potencial mais amplo, adotou-se um valor de mercado potencial relativamente pequeno.

Assume-se que o preço do outside good $n$ é zero, $p_{n}=0$, de modo que a sua utilidade seja constante. Seja $\mathbf{p}=\left[p_{1} \ldots p_{\mathrm{n}-1}\right]$ o vetor de preços dos demais bens e $\mathbf{s}=\left[\begin{array}{lll}s_{1} & \ldots & s_{\mathrm{n}-1}\end{array}\right]$ as correspondentes parcelas de mercado (market shares). O preço médio ponderado por market share é dado por $\bar{p}=\mathbf{p}^{\prime}$ s. Os market sharesrepresentam as probabilidades condicionais de escolha para os bens do mercado, exceto o outside good. Note que a expressão (2), que descreve a probabilidade de escolha do indivíduo $i$ por um bem $j$ determinada pelo modelo, na prática, é substituída pelo seu share de mercado.

Fazendo a diferença dos logaritmos do share de mercado do bem $j$ e do share de mercado do outside good, obtém-se ${ }^{12}$ :

$$
\log \left(s_{j}\right)-\log \left(s_{0}\right)=\alpha_{j}-\beta p_{j}+e_{i j}
$$

Os parâmetros da equação (3), particularmente $\beta$, podem ser facilmente estimados por técnicas econométricas tradicionais de variáveis instrumentais, dado que preços estão correlacionados com o erro. Nessas condições, as elasticidades-preço próprias e cruzadas da demanda para bens $j$ e $k$ são descritas, respectivamente, por:

$$
\varepsilon_{j j}=-\beta \cdot p_{j}\left(1-\operatorname{Pr}_{i j}\right)=-\left[\beta \cdot \bar{p}\left(1-s_{j}\right)+\varepsilon s_{j}\right] p_{j} / \bar{p}
$$

\footnotetext{
$11 \mathrm{O}$ valor da informação mais recente do mercado foi projetado para datas anteriores, de modo que se supõe um mercado potencial fixo no tempo.

12 Essa expressão pode ser avaliada como o resíduo estimado.
} 


$$
\varepsilon_{j k}=\beta \cdot p_{k} \operatorname{Pr}_{i k}=s_{k}(\beta \cdot \bar{p}-\varepsilon) p_{k} / \bar{p}
$$

A elasticidade-preço da demanda agregada implicada para os bens "inside", isto é, sem incluir o outside good, corresponde a:

$$
\varepsilon=-\beta \cdot \bar{p} \cdot \operatorname{Pr}_{\text {insi deg oods }}=\varepsilon=-\beta \cdot \bar{p} \cdot s_{\text {insidegoods }}
$$

Deste modo, a partir das primitivas share da indústria, s, preços, $\mathbf{p}$, que são observáveis e dos parâmetros $\beta$ e $\varepsilon$, que podem ser estimados, é possível obter as elasticidades-preço dos produtos diferenciados. $\beta$ corresponde ao parâmetro da elasticidade cruzada da demanda, controlando a substituição entre os inside goods, ao passo que $\varepsilon$ corresponde ao parâmetro da elasticidade-preço da demanda agregada, controlado pela substitutabilidade entre os inside goods e o outside good.

Pelo fato de se adotar a hipótese de "independência das alternativas irrelevantes" (IIA do inglês independence of irrelevant alternatives), o modelo Logit implica em uma assimetria no padrão de substituição entre os bens, conhecida como deslocamento proporcional (proportional shifting). Assim, se houver melhora de avaliação de utilidade de um bem, haverá um deslocamento proporcional à participação de mercado de cada bem em sua direção.

Este padrão de substituição, que decorre do fato de as elasticidades-preço cruzadas dependerem apenas da estimativa de $\beta$, do preço médio do produto substituto, $p_{k}$, e do share do substituto, $s_{k}$, muitas vezes é considerado pouco realista para a maioria dos mercados analisados em antitruste. O exemplo clássico apontado por Berry et al. (1995) é que a redução da participação de mercado de um automóvel importado, por exemplo, resulta, sob o modelo Logit, em um impacto semelhante de aumento de consumo de automóveis de luxo e de carros populares, que são produtos com características bem distintas. Assim, a hipótese de alternativas irrelevantes não é capaz de condicionar a escolha a características específicas. Entretanto, considerando-se o mercado de café, em que se sabe que a substituição para a composição do blend é corriqueira, não há problemas com a adoção desta hipótese, principalmente quando se leva em conta a inovação na secagem do café robusta mencionada anteriormente.

Deve-se notar, entretanto, que os valores das elasticidades-preço próprias dependem de maneira significativa do nível de preços, de modo que produtos com preços maiores ficam atrelados a elasticidades maiores em módulo. Assim, o modelo Logit, apesar de ter sucesso em reduzir o número de parâmetros a serem estimados, gera um padrão de elasticidades-preço crescente nos preços. Essa simplificação, no entanto, não suscita maiores preocupações, uma vez que esta relação entre elasticidade e preços é bastante razoável e intuitiva na análise econômica.

O comportamento dos ofertantes pode ser avaliado, em análise de concorrência, por condições de entrada e rivalidade através de testes de instabilidade de share. Quando a participação relativa do mercado é instável, tal resultado pode indicar efeito de concorrência.

Gallet e List (2001) testaram a estacionariedadeda razão entre os market shares de algumas firmas do segmento de cigarros e o share médio dos mercados. Seguindo esta mesma metodologia, testamos a instabilidade dosmarket shares dos exportadores mundiais de café, com vistas a captar a existência de rivalidade neste mercado. O teste de instabilidade de share proposto por Levin e Lin (LL) e desenvolvido por Levin, Lin and Chu (LLC), 2002, impõe que o parâmetro que mede a estacionariedade do painel de dados seja igual para os diferentes agentes econômicos (no caso, países exportadores de café). Deste modo, os indivíduos possuem o mesmo coeficiente autorregressivo de primeira ordem, $\mathrm{AR}(1)$. O procedimento pode ser interpretado como um teste de Dickey-Fuller na forma de dados empilhados (pooled data), ou como um teste de Dickey-Fuller aumentado (ADF) em que as defasagens são incluídas, com hipóteses nulas de não estacionaridade (sendo integradas de ordem 1).

Após a transformação por fatores proposta por LLC, a estatística t de teste apresenta distribuição 
normal sob a hipótese nula de não estacionaridade. Este teste tende a apresentar vantagem em relação ao teste ADF multivariado de Taylor e Sarno(1998) por permitir o uso de amostras pequenas no tempo e grandes no painel. No caso do último teste, o modelo é estimado por estimador SUR (do inglês seemingly unrelated regressions).

Considerando-se as limitações do teste LL (também conhecido como modelo de painel homogêneo) Im, Pesaran e Shin (1997), (IPS), propõem o modelo de painel heterogêneo. Conforme Maddala e Kim (1998), este modelo flexibiliza a hipótese de homogeneidade, mantendo a mesma estrutura do teste. Assim, este tem sido o teste mais frequentemente utilizado nas aplicações empíricas de testes de raiz-unitária para painel.

O procedimento do teste, conforme Resende e Lima (2005), pode ser resumido na seguinte equação:

$$
\begin{aligned}
& \Delta y_{i, t}=\alpha_{i}+\beta_{i} y_{i, t-1}+\varepsilon_{i, t} \\
& i=1, \ldots, N \quad t=1, \ldots, T
\end{aligned}
$$

O parâmetro de interesse para testar a estacionariedade da variável $y$ é $\beta_{i}$, estimado a partir de um teste ADF aumentado em painel. A diferença em relação ao modelo LL é que, neste último, $\beta$ é o mesmo para todos os agentes, além da distribuição assintótica da estatística do teste.

As seguintes hipóteses nulas estão envolvidas no teste IPS:

$$
\mathrm{H}_{0}: \beta_{\mathrm{i}}=0 \forall \mathrm{i} \text { and } \mathrm{H}_{1}: \exists \mathrm{i} \text { tal que } \beta_{\mathrm{i}}<0
$$

A estatística de teste ( $\bar{t}$ "t-barra", conhecida como Psi-bar) é a média das estatísticas individuais dos testes ADF, $\tau_{\mathrm{i}}$ :

$$
\bar{t}=\frac{1}{N} \sum_{i=1}^{N} \tau_{i}, \quad \text { sendo } \quad \tau_{i}=\frac{\hat{\beta}_{i}}{\hat{\sigma}_{\hat{\beta}_{i}}}
$$

Em que: $\left(\sqrt{N}\left(\bar{t}-\mathrm{E}\left(\tau_{\mathrm{i}} \mid \beta_{\mathrm{i}}=0\right) /\left(\operatorname{Var}\left(\tau_{\mathrm{i}} \mid \beta_{\mathrm{i}}=0\right)\right.\right.\right.$ $1 / 2) \sim \mathrm{N}(0,1)$

O teste mantém as mesmas possibilidades de LL, de modo a permitir a inclusão de uma tendência determinística, além de efeitos temporais. Entretanto, no teste LL a alternativa é que todas as variáveis são estacionárias, enquanto no teste IPS a rejeição da hipótese nula, que implica variáveis não estacionárias, é compatível com a existência de um grupo de variáveis estacionárias e outro grupo de variáveis não estacionárias.

Deve-se notar que a possibilidade de se realizar tanto os testes para cada série de tempo (representando o share relativo de uma firma em relação ao mercado) quanto os testes para painel pode sugerir robustez dos resultados, caso haja convergência entre eles.

Por fim, deve-se observar que, em mercados competitivos, espera-se que os markets shares detidos pelas empresas sejam instáveis, uma vez que a concorrência imposta pelas empresas rivais e pelas potenciais entrantes não permite estabilidade de mercado a ofertantes específicos.

\section{Resultados}

A base de dados, obtida junto à ICO, compreende as quantidades exportadas e os preços médios mensais, de 1988 a 2009, por tipo de café verde (robusta, arábica suave, arábica natural e outras variedades). A partir destas informações, foram estimadas as elasticidades-preço próprias e cruzadas da demanda por cafés do tipo verde. Para a composição de cada série de quantidades exportadas por tipo de café foram agregadas as exportações de todos os países que exportaram café por tipo de café. Este procedimento foi necessário porque as séries de preços disponíveis estavam agregadas por tipos de café13. A Tabela A1 no anexo mostra quais exportadores foram incluídos em cada variedade. Os resultados das estimativas são mostrados na Tabela 2 .

Os resultados das elasticidades-preço da demanda por café verde, obtidos a partir da estimação do ALM, mostram que, tanto

\footnotetext{
13 Não dispúnhamos de dados de preços por país, apenas por variedade. Mas, para o caso do Brasil, a análise se aplica porque é o País que produz quase a totalidade de arábica natural.
} 
a elasticidade-preço própria do café arábica brasileiro quanto a do café robusta são menores que a unidade, em valor absoluto. Portanto, a demanda para estas duas variedades apresentam um padrão menos elástico a preços do que a demanda para o café colombiano e de outras variedades. As elasticidades-preço cruzadas da demanda em relação ao café verde brasileiro mostram que a maior substituição deste ocorre pelo café robusta. É importante notar que a variância das elasticidades-preço da demanda das variedades é significativamente menor do que os valores encontrados por Bacha (1970) em período anterior. De acordo com este autor, países que seguiam a estratégia de preços do Brasil apresentavam valores de elasticidades-preço próprias da demanda em torno de -0,30; para os que não seguiam o valor de sua elasticidade-preço, era de $-1,29$. Na verdade, os resultados obtidos aqui sugerem que a elasticidade-preço da demanda da espécie brasileira se aproximou mais do valor das demais espécies, confirmando, assim, uma mudança de padrão de resposta dos demandantes ao café brasileiro.

A fim de se identificar a demanda de market share estimada e calcular as correspondentes elasticidades, utilizou-se o Método dos Momentos Generalizados (GMM), usando como instrumentos a produtividade marginal do trabalho e a área útil cultivável por pessoa (vide tabela A2 no anexo, primeira coluna), obtidas do Internacional Financial Statistics do FMI. Os instrumentos passaram no teste de Sargan e têm $\mathrm{R}^{2}$ do primeiro estágio maior que $10 \%$. Outros instrumentos, como preços defasados, geram estatísticas muito parecidas, mesmo quando Sargan não foi satisfeito.
Os resultados obtidos para o lado da oferta e os testes de market share para as quantidades indicam haver estabilidade de market share entre 1990 e 2009 para os tipos de café em todas as especificações testadas (Tabela 3) com até cinco defasagens com e sem tendência. Considerando-se o enorme e recente crescimento do Vietnã no mercado internacional, o esperado seria a não rejeição da hipótese nula de não estacionaridade, o que indicaria haver rivalidade no mercado. Entretanto, não se pode concluir que não há competição neste mercado, uma vez que a hipótese alternativa contempla que pode haver apenas um exportador estacionário e os demais não estacionários, o que indicaria rivalidade. Neste mercado, ao menos um exportador tem comportamento estável.

Além disso, dois outros fenômenos precisam ser considerados: (i) os dados disponíveis para a análise são agregados de países exportadores por tipos de café - robusta, arábica suave, arábica natural e outras variedades - e podem não revelar o padrão de concorrência efetivo no mercado. Isso porque podem ocorrer mudanças compensatórias em termos de share de quantidade, tais como o aumento de exportação do café robusta pelo Vietnã concomitante com a queda de exportação desta variedade pela Uganda ou, ainda, o aumento da quantidade exportada de café arábica brasileiro, concomitante com a queda na quantidade exportada pela Colômbia. Deste modo, os shares de quantidade por tipo de café podem não se alterar de maneira não estacionária no tempo; (ii) em geral, os testes de instabilidade de market share são conduzidos pelos valores e não pelas quantidades, uma vez que estes refletem melhor as mudanças de preços relativos.

Tabela 2. Elasticidades-preço por tipo de café verde: próprias, cruzadas e do mercado mundial de café verde.

\begin{tabular}{lcc}
\hline \multicolumn{1}{c}{ Variedade } & Elasticidade própria & Elasticidade cruzada da variedade brasileira \\
\hline Arábica brasileiro & -0.87 & - \\
Arábica colombiano & -1.403 & 0.168 \\
Arábica outros & -1.259 & 0.169 \\
Robusta & -0.717 & 0.273 \\
Café verde & $-0,245$ & - \\
\hline
\end{tabular}


Tabela 3. Teste de raiz unitária em painel

\begin{tabular}{ccc}
\hline \multicolumn{3}{c}{ Modelo sem tendência } \\
\hline Defasagens & $t$-bar & $p$-value \\
\hline $\mathrm{p}=1$ & -5.42 & 0.00 \\
$\mathrm{p}=2$ & -5.515 & 0.00 \\
$\mathrm{p}=3$ & -5.515 & 0.00 \\
$\mathrm{p}=4$ & -5.386 & 0.00 \\
$\mathrm{p}=5$ & -4.65 & 0.00 \\
\hline \multicolumn{3}{c}{ Modelo com tendência } \\
\hline Defasagens & $\boldsymbol{t}$-bar & $p$-value \\
\hline $\mathrm{p}=1$ & -6.897 & 0.00 \\
$\mathrm{p}=2$ & -7.259 & 0.00 \\
$\mathrm{p}=3$ & -7.271 & 0.00 \\
$\mathrm{p}=4$ & -6.527 & 0.00 \\
$\mathrm{p}=5$ & -6.038 & 0.00 \\
\hline
\end{tabular}

Vale notar que o uso das quantidades, e não do valor, está associado com distintas fontes de informação ${ }^{14}$ - de uma fonte, preços por tipo de café e de outra, as quantidades por país e por tipo de café - que conduziu à análise de modo a ser cautelosa e conservadora sobre compor os valores. Esses problemas serão dirimidos em desenvolvimentos futuros deste estudo com a obtenção de dados de fontes comuns.

\section{Conclusões e considerações do estudo}

Este estudo buscou gerar estimativas preliminares sobre a demanda mundial de café verde e sobre comportamentos dos ofertantes para avaliar o grau de competição deste mercado nos últimos 20 anos, em particular sobre o segmento de café arábica natural. Esta é a variedade de café majoritariamente exportada pelo Brasil.

Os resultados das elasticidades-preço estimadas pelo sistema de demanda Logit Multinomial Antitruste (ALM, do inglês Antitrust Logit Multinomial) sugerem uma menor dispersão entre as elasticidades-preço das diferentes variedades de café em relação às estimativas para períodos anteriores. Além disso, apontam o café robusta, produzido pelo Vietnã, como o principal substituto

14 Isso para manter a maior amostra possível de dados. da variedade brasileira de café verde, o arábica natural. Deste modo, identifica-se um padrão mais elástico de demanda mundial de café verde para a variedade brasileira de café, portanto, de maior concorrência para este segmento.

Entretanto, os resultados dos testes de instabilidade de sharede quantidade, realizados por testes de cointegração em painel, que avaliam o comportamento de equilíbrio de mercado, indicam não haver rivalidade/entrada provável no mercado mundial de café verde para todos os seus tipos - robusta, arábica suave, arábica natural e outras variedades. Apesar disso, não se pode concluir pela ausência de competição por três motivos: (i) por dificuldades de obtenção de dados, foram utilizadas quantidades, e não valores, para compor os shares de mercado, sendo que estes últimos são mais indicados para a análise; (ii) os exportadores de café estão agregados por tipo de café e esta agregação pode apresentar movimentos compensatórios, aumentos de alguns exportadores e queda de outros no mesmo tipo de café; e (iii) o teste IPS tem como hipótese alternativa que pelo menos um exportador pode ter estabilidade de share, sendo que os demais podem não apresentar necessariamente um padrão estável. $\mathrm{O}$ conceito de rivalidade define a existência ou não de forças competitivas impostas por outros produtores de mercado. A entrada provável indica que existe espaço para novos produtores no mercado, que podem entrar e se estabelecer rapidamente, como foi o caso do Vietnã e de alguns outros produtores asiáticos.

A conjugação dos resultados obtidos para demanda e oferta sugere que a estabilidade de mercado em quantidade da variedade brasileira de café verde pode estar sendo mantida por meio de reduções de preços no mercado internacional, uma vez que se verifica uma menor dispersão das elasticidades-preço das diferentes variedades de café. Deste modo, poder-se-ia inferir que o Brasil continua sendo um grande player, mas com menos poder de influenciar preços. Estas conclusões ainda devem ser investigadas a partir de novos estudos a serem realizados sobre o tema, dadas as limitações do presente artigo. 


\section{Referências bibliográficas}

BACHA, E. L. Análise Econométrica do Mercado Internacional de Café e da Política Brasileira de Preços. Ensaios Econômicos da EPGE, n. 2. Instituto Brasileiro de Economia da Fundação Getúlio Vargas, 1970.

BEN-AKIVA, M. e LERMAN, S. Discrete Choice Analysis: Theory and Application to Travel Demand (Transportation Studies), Massachusetts: MIT Press, 1985.

BERRY, S., LEVINSOHN, J. e PAKES, A. "Automobile Prices in Market Equilibrium". Econometrica, v. 63, 841-890, 1995.

CHI, T.Q; TUAN, N.D.A; LAN, N.N. Coffee yearbook in 2008 \& Outlook for 2009. Ministry of Agriculture and Rural Development. Institute of Policy and Strategy for Agriculture and Rural Development, February, 20 p. (não publicado), 2009.

CUNHA, D. A. Integração de preços no mercado internacional de café. Universidade Federal de Viçosa, Dissertação de Mestrado, junho, 2008.

DESOUZA, S.A. The Antitrust Mixed Logit Model. Série Estudos do CAEN, 2009.

GALLET, C.A.; LIST, J.A. Market Share Instability: an Application of Unit Root Tests for the cigarette Industry, Journal of Economics and Business, 53, 473-80, 2001.

HAEBERLIN, I.B.; TEIXEIRA, E.C.; KAM-CHINGS, M.H.L. Análise do Impacto do Rompimento do Acordo Internacional do Café sobre o Brasil e Colômbia. Revista de Economia e Sociologia Rural, vol. 31. no. 1 (jun-mar): p; 9-22, 1993.

IM, K.; PESARAN, H; SHIN, Y. Testing for Unit Roots in Heterogeneous Panels, Discussion Paper, University of Cambridge, June, 1997.

INTERNATIONAL COFFEE ORGANIZATION (ICO). Statistics. Historical Data. Disponível em: <ttp://www. ico.org >. Acesso em: 2010.

LAZARINI, S.G.; SAES, M.S.M.; NAKAZONE, D. Competição entre Bolsas de Futuros: o caso BM\&F e da CSCE no Mercado do Café. Revista de Economia Aplicada, São Paulo, v. IV, n. 2, 2000.

LEVIN, A.L.; LIN, C.F.; CHU C.S.J. Unit Root Tests in Panel Data: Asymptotic and Finite Sample Properties. Journal of Econometrics, 108, 1-24, 2002.

MADDALA, G.S.; KIM I.M. Unit Roots, Cointegration, and Structural Change, Cambridge: Cambridge University Press, 1998.

MCFADDEN, D. "Modeling the Choice of Residential Location". In A Karl-gvist, et al. eds., Spatial Interaction Theory and Planning Models, Amsterdam: NorthHolland, 1978.

RESENDE, M.; LIMA, M.A.M. Market share instability in Brazilian industry: a dynamic panel data analysis. Applied Economics. v. 7 , issue 6, 2005.

SAES, M.S.M.; FARINA, E.M.M.Q. O Agribusiness do Café do Brasil. São Paulo: Editora Miilkbizz, 1999.

SAES, M.S.M. Estratégias de Diferenciação e Apropriação da Quase-Renda na Agricultura. São Paulo: Annablume/ Fapesp, 197 p., 2009.

TAYLOR, M. P.; SARNO, L. The Behavior of Real Exchange Rates During the Post-Bretton Woods Period. Journal of International Economics. 46:2, pp. 281-312.1998

TRAIN, K. Discrete Choice Methods with Simulation. Cambridge University Press, 2sd edition, 2009.

WERDEN, G.J; FROEB, L.M. The Effects of Mergers in Differentiated Products Industries: Logit Demanda and Merger Policy. The Journal of Law, Economics \& Organization, v10, n2, 1994.

WERDEN, G.J.; FROEB, L.M. TARDIFF, T.J. “The Use of Logit Model in Applied Industrial Organization" International Journal of the Economics of Business 3: 83-105, 1996.

WERDEN, G. Demand Elasticities in Antitrust Analysis", Antitrust Law Journal, vol. 66, 1998. 


\section{Anexos}

Tabela a. Exportadores incluídos em cada variedade de café.

\begin{tabular}{|c|c|c|c|}
\hline Colombian Milds & Other Milds & Brazilian Naturals & Robusta \\
\hline Colômbia & Bolívia & Brasil & Angola \\
\hline Quênia & Burundi & Etiópia & Benin \\
\hline \multirow[t]{25}{*}{ Tanzânia } & Camarões & Indonésia & Brasil \\
\hline & Congo & Filipinas & Burundi \\
\hline & Costa Rica & & Camarões \\
\hline & Cuba & & República Centro Africana \\
\hline & República Dominicana & & Congo \\
\hline & Equador & & Costa do Marfim \\
\hline & El Salvador & & Equador \\
\hline & Guatemala & & Gabão \\
\hline & Haiti & & Gana \\
\hline & Honduras & & Guiné \\
\hline & Índia & & Índia \\
\hline & Jamaica & & Indonésia \\
\hline & Madagascar & & Madagascar \\
\hline & Malawi & & Nigéria \\
\hline & México & & Papua Nova Guiné \\
\hline & Nicarágua & & Filipinas \\
\hline & Panamá & & Serra Leoa \\
\hline & Papua Nova Guiné & & Sri Lanka \\
\hline & Peru & & Tanzânia \\
\hline & Ruanda & & Tailândia \\
\hline & Sri Lanka & & Togo \\
\hline & Uganda & & Trinidade e Tobago \\
\hline & Venezuela & & Uganda \\
\hline & Zâmbia & & Vietnã \\
\hline & Zimbabwe & & \\
\hline
\end{tabular}

Fonte: Elaborado pelos autores com base em informações da ICO (2010). 
Tabela b. Estimativas de demanda por market share com diferentes instrumentos

\begin{tabular}{cccccc}
\hline \multirow{2}{*}{ Variáveis } & $\mathbf{( 1 )}$ & $\mathbf{( 2 )}$ & $\mathbf{( 3 )}$ & $\mathbf{( 4 )}$ & $\mathbf{( 5 )}$ \\
\cline { 2 - 6 } & $\mathbf{y}$ & $\mathbf{y}$ & $\mathbf{y}$ & $\mathbf{y}$ & $\mathbf{y}$ \\
\hline $\mathrm{P}$ & $-0.0126^{* * *}$ & $-0.0117^{* * *}$ & $-0.0126^{* * *}$ & $-0.0116^{* * *}$ & $-0.0129^{* * *}$ \\
& $(0.000691)$ & $(0.000599)$ & $(0.000670)$ & $(0.000557)$ & $(0.000696)$ \\
\hline \multirow{2}{*}{ Tendência } & $-0.00925^{* *}$ & $-0.00914^{* *}$ & $-0.0120^{* * *}$ & $-0.00713^{* *}$ & $-0.00961^{* * *}$ \\
& $(0.00367)$ & $(0.00357)$ & $(0.00358)$ & $(0.00342)$ & $(0.00371)$ \\
\hline \multirow{2}{*}{ Constant } & -0.222 & -0.342 & $-2.418^{* * *}$ & -0.721 & -0.105 \\
& $(0.776)$ & $(0.749)$ & $(0.0753)$ & $(0.723)$ & $(0.788)$ \\
\hline Observations & & & & & \\
\hline R-squared & 864 & 864 & 848 & & 848 \\
\hline
\end{tabular}

Notas: ${ }^{* *} \mathrm{p}<0.01,{ }^{* *} \mathrm{p}<0.05,{ }^{*} \mathrm{p}<0.1$ (Robust standard errors in parentheses).

Dummies de ano incluídas.

Fonte: Elaborado pelos autores com base em informações da ICO (2010).

Tabela c. Instrumentos das estimativas de demanda por market share.

\begin{tabular}{lccc}
\hline & R2 - Primeiro estágio & Instrumentos & Sargan $p$-valor \\
\hline modelo (1) & 0.4288 & lpmgt terra_aravel & 0.308 \\
modelo (2) & 0.4801 & lpmgt terra_aravel dtipo* & 0.000 \\
modelo (3) & 0.4528 & lpmgt terra_aravel p_4 & 0.063 \\
modelo (4) & 0.5037 & lpmgt terra_aravel p_4 dtipo* & 0.000 \\
modelo (5) & 0.4304 & lpmgt terra_aravel p_5 & 0.395 \\
\hline
\end{tabular}

Notas: 1 pmgt $=$ produtividade marginal do trabalho; terra arável=quantidade de terra arável; $\mathrm{p}_{-} 4=$ preço defasado em 4 períodos; $\mathrm{p} \_5$ = preço defasado em cinco períodos; d tipo = dummy de tipos de café.

Fonte: Elaborado pelos autores com base em informações da ICO (2010). 